\title{
Isolation, Identification and Taxonomic affiliation of Exopolysaccharide Producing lactic acid bacteria from Kradi cheese
}

\author{
Hilal Ahmad Punoo ${ }^{1 *}$ \\ ${ }^{1}$ Department of Food Science and Technology, University of Kashmir Hazratbal Srinagar \\ J\&K INDIA. \\ *Corresponding author \\ Email:hilalpunoo@gmail.com \\ Tel.: +91-9419024079; fax: +91-194-2272096
}

\begin{abstract}
Kradi cheese is manufactured by coagulation of naturally fermented butter milk containing different strains of lactic acid bacteria. In this study lactic acid bacterial strains were isolated from kradi cheese and screened for exopolysaccharide potential. The taxonomic group of the exopolysaccharide producing lactic acid bacterial strains was determined on the basis of their 16S rRNA sequences. Nine strains were shown to produce exopolysaccharides in MRS medium with sucrose. Four strains belonged to lactococcus lactis subsp. lactis and five strains to Lactococcus lactis subsp. cremoris species. Isolated strains showed varied yield of exopolysaccharides. The exopolysaccharides had high molecular mass of $1500 \mathrm{kDa}$ and glucose was dominant in their monomer composition.
\end{abstract}


Keywords: lactic acid bacteria, isolation, taxonomic affiliation, exopolysaccharides, monomer composition

\section{Introduction}

Exopolysaccharides are natural polymers water soluble and have long chain high molecular mass (Deepak et al. 2016a; Deepak et al. 2016b). Lactic acid bacteria produce exopolysaccharides (EPS) which show lot of structural diversity (Bernal and Liamsa 2012; Ruas Madiedo 2002). Exopolysaccharides may be released into surrounding environment or loosely bound to cell surface (Abedfar and Hossininezhad 2016; Ram Kumar Pandian et al. 2016; Deepak et al. 2016b; Patel et al. 2012). Exopolysaccharides biosynthesis is controlled by many enzymes and proteins which are controlled through regulation by gene expression (Ciszek-Lenda 2011). The nature of exopolysaccharides depends on strain, culture condition and media composition. Lactic acid bacteria are present in fermented dairy products. Kradi cheese is a traditional indigenous cheese produced in Jammu and Kashmir India (Punoo et al. 2018a and Punoo et al. 2018b) by Gujjar tribes residing in green pastures. The raw material for kradi cheese production is naturally fermented raw milk which contains different strains of lactic acid bacteria (LAB). In the present study different strains of lactic acid bacteria from kradi cheese were isolated, identified and recognized for exopolysaccharide production. The taxonomic affiliation of exopolysaccharide producing bacteria was also verified.

\section{Materials and Method}

\subsection{Lactic acid bacterial strains, growth conditions, screening for EPS production}

The nine LAB used throughout this study were isolated from kradi cheese. These strains were isolated by plating on MRS agar (De Mann et al. 2013). Also modified MRS agar with $50 \mathrm{~g} / 1$ of sucrose (MRS-s) and modified MRS agar with $20 \mathrm{~g} / 1$ of fructose (MRS-f) were used as isolation media. All the strains were stored at $-85^{\circ} \mathrm{C}$ in their corresponding isolation medium, containing $25 \%(\mathrm{v} / \mathrm{v})$ of glycerol as a cryoprotectant. LAB strains were propagated twice in fresh liquid medium for obtaining fresh culture from frozen stock, before the experiments. LAB strains were grown in MRS-s while screening for EPS production. The glucomannans in the growth medium which could interfere with the EPS screening were removed (Vander Meulen et al. 2007). The LAB strains were screened for EPS production by Gel Permeation 
Chromatography (GPC), using a Jasco HPLC System (Jasco Europe, Cremella, Italy), equipped with an Ultra-hydrogel Linear column (Waters Corp., Milford, Mass., USA), kept at $35^{\circ} \mathrm{C}$, and coupled to RI-2031 refractive index detector (Jasco). Samples were prepared (Vander Meulen et al. 2007) prior to the injection on the GPC column. The EPS were eluted with $0.1 \mathrm{M} \mathrm{NaNO}_{3}$ at a flow rate of $0.6 \mathrm{ml} / 1$. Dextran standards with molecular masses ranging from $80 \mathrm{kDa}$ to $1.4 \mathrm{MDa}$ (Sigma-Aldrich, Switzerland) were used to calculate the molecular mass of the purified EPS.

\subsection{Taxonomic identification of EPS-producing LAB strains}

The taxonomic affiliation of the EPS-producing LAB strains was determined on the basis of their 16S rRNA sequence. PCR amplification of 16S rRNA gene and purification were performed (Stancu 2012). Sequencing of amplification products was performed by biotechnology division of university. DNA sequencing runs were assembled using the BioEdit software. The sequences were compared to those from databases using the BLAST search program.

\subsection{Isolation of EPS and quantification}

EPS were isolated from GPC positive LAB strains according to a two-step precipitation protocol (DeVusy et al. 1998). The LAB strains were cultivated in filtered MRS-s for $12 \mathrm{~h}$, with no $\mathrm{pH}$ control or agitation. Total EPS yields was determined gravimetrically by measuring the polymer dry mass (PDM) after $48 \mathrm{~h}$ of drying at $42^{\circ} \mathrm{C}$. The further purification of the EPS was done by ultrafiltration using a Vivaspin 6 ultrafiltration module with a 10-kDa MM cut-off (Sartorius Stedim Biotech GmbH, Goettingen, Germany). The retentate obtained after two centrifugation steps was adjusted to $2 \mathrm{ml}$ with ultra pure water and used for further analysis.

\subsection{Monomer analysis}

The purified EPS were hydrolyzed for $6 \mathrm{~h}$ at $100^{\circ} \mathrm{C}$ with $8 \mathrm{~N} \mathrm{HCl}$, evaporated in an Eppendorf AG centrifugal concentrator (Eppendorf, Hamburg, Germany) and re-suspended in ultrapure water. Monosaccharide composition of EPS was determined by automated thin-layer chromatography (TLC) (CAMAG, Muttenz, Germany) using the ascending technique with silica gel 60 F254 precoated glass sheets (Merck, Damstadt, Germany). The sugars were eluted with a mixture of 1-butanol/acetic acid/water, 6/1/2 (v/v) and the bands were visualized by spraying with p-aminobenzoic acid (Wall, 2005). Glucose, galactose, rhamnose, manose, ribose, xylose (Fluka, Sigma-Aldrich, Switzerland), fructose (Merck KGaA, Darmstadt, 
Germany), arabinose (Veb Berlin Chemie, Germany), glucosamine and galactosamine (both from Calbiochem, Inc. San Diego, Calif., USA) were used as standards. In another option, HPLC was used to determine the sugar composition of the hydrolyzed EPS. A Jasco HPLC system (Jasco Europe, Cremella, Italy), equipped with a Carbo Sep Coregel 87Pcolumn (Teknokroma, Spain), kept at $85{ }^{\circ} \mathrm{C}$, and coupled with a RI-2031 refractive index detector (Jasco) was used for separation. Elution was performed with MilliQ water, at a flowrate of 1 $\mathrm{ml} / \mathrm{min}$. Arabinose, fructose, galactose, glucose, maltose, mannose, rhamnose, ribose, sorbose, sucrose, and xylose at a concentration of $0.1 \mathrm{mg} / \mathrm{ml}$ were used as standards.

\section{Results and Discussion:}

In addition to plant products, indigenous dairy based products like kradi cheese play an important role in the cooking habit of people of jammu kashmir and are still unexplored food ecological place. These indigenous dairy products of jammu kashmir are known for their beneficial effect on humans, due to presence of probiotic lactic acid bacteria. The literature data available regarding microbial content of kradi cheese is limited (Punoo et al. 2018).

Kradi cheese is produced by coagulation of mixture of part of naturally fermented raw buttermilk and milk. The fermented raw buttermilk used in kradi cheese production is the source of LAB. In the present study LAB strains were isolated from kradi cheese and screened for EPS production. EPS were isolated, purified and monomer analysis was done.

\subsection{Screening and Identification of LAB strains for Exopolysaccharide production}

Nine lactic acid bacterial strains having exopolysaccharide production potential were screened by gel permeation chromatography. The results showing less number of EPS positive strains agreed with others (Grosu-tudor and Zamfir 2013a).

The nine EPS producing strains determined by the 16S rRNA gene sequencing comprised four strains of Lactococcus lactis subsp. lactis and five strains of lactococcus lactis subsp. cremoris (Table1). In fermented dairy products Leuconostoc strains had been tested for EPS production at high occurrence (Grosu-tudor et al. 2013b). 
Table 1 Taxonomic association of the EPS producing LAB strains

\begin{tabular}{|c|c|c|}
\hline S. No & Strain name & Species \\
\hline 1 & Q 14 & L. lactis subsp. lactis \\
\hline 2 & Q 20 & L. lactis subsp. lactis \\
\hline 3 & G 50 & L. lactis subsp. lactis \\
\hline 4 & C 59 & L. lactis subsp. lactis \\
\hline 5 & F 16 & L. lactis subsp. cremoris \\
\hline 6 & H 17 & L. lactis subsp. cremoris \\
\hline 7 & H 21 & L. lactis subsp. cremoris \\
\hline 8 & H 41 & L. lactis subsp. cremoris \\
\hline 9 & H 61 & L. lactis subsp. cremoris \\
\hline
\end{tabular}

\subsection{Isolation and characterization of Exopolysaccharides}

Exopolysaccharides were isolated in various amounts from all the Gel Permeation chromatography positive strains. The EPS yield was high in case of Lactococcus lactis subsp. lactis Q 20 strain about $18.6 \mathrm{~g} / \mathrm{l}$. The EPS yield in case of Lactococcus lactis subsp. lactis $\mathrm{G}$ 50 strain was $9 \mathrm{~g} / 1$ which was similar with the two strains of lactococcuc lactis subsp. cremoris $\mathrm{H} 17$ and H 21 (Table 2). EPS yield in case of L. lactis subsp. lactis Q 14 was $4.2 \mathrm{~g} / 1$. The EPS yield in case of L. lactis subsp. lactis strain C 59 was $2 \mathrm{~g} / 1$ which was similar with the two strains of lactococcus lactis subsp. cremoris F 16 and H 4. Ullrich 2009 has reported EPS yield of about $50 \mathrm{~g} / 1$ for Leuconostoc species. Grosu-Tudor and Zamfir 2013 has reported EPS yield of about $10 \mathrm{~g} / \mathrm{l}$ by LAB obtained from fermented milk. All the EPS eluted revealed in Gel permeation chrmatograpghy chromatogram molecular mass of higher than 1.5 MDa. Grosu-Tudor and Zamfir 2013 have reported high molecular mass of EPS produced by LAB strains from fermented milk (Grosu-Tudor et al. 2013). Ruas-Madiedo et al 2002 reported that estimation of the molecular mass of exopolysaccharides is essential for their characterization which affects rheological properties. 
Table 2 EPS producing strains and EPS yield isolated from MRS-s cultures

\begin{tabular}{|c|c|c|c|c|}
\hline Species & Strain name & EPS Yield (g/l) & Molecular mass & $\begin{array}{c}\text { Monomer } \\
\text { composition }\end{array}$ \\
\hline L. lactis subsp. lactis & Q 14 & $4.2 \pm 0.7$ & \multirow{9}{*}{$>1.5 \mathrm{MDa}$} & \multirow{9}{*}{ Glucose } \\
\hline L. lactis subsp. lactis & Q 20 & $18.6 \pm 0.2$ & & \\
\hline L. lactis subsp. lactis & G 50 & $9.0 \pm 0.0$ & & \\
\hline L. lactis subsp. lactis & C 59 & $2.0 \pm 0.0$ & & \\
\hline L. lactis subsp. cremoris & F 16 & $2.0 \pm 0.0$ & & \\
\hline L. lactis subsp. cremoris & H 17 & $9.0 \pm 0.0$ & & \\
\hline L. lactis subsp. cremoris & H 21 & $9.0 \pm 0.0$ & & \\
\hline L. lactis subsp. cremoris & H 41 & $2.0 \pm 0.0$ & & \\
\hline L. lactis subsp. cremoris & H 61 & $1.8 \pm 0.1$ & & \\
\hline
\end{tabular}

By thin layer chromatography several bands of isolated monomers of EPS were observed of hydrolyzed samples. From TLC bands glucose $(\mathrm{Rf}=0.277)$ was major band whereas other bands could not confirm for monosaccharide or oligosaccharides. The presence of glucose monomer was confirmed by HPLC analysis of EPS isolated from L. lactis subsp. lactis Q 20.

\section{Conclusion:}

This study reveals that kradi cheese manufactured from coagulation of naturally fermented raw milk contains LAB strains with exopolysaccharide production potential. These isolated exopolysaccharides can be used as viscosifiers, emulsifiers, stabilizing agents with application in improvement in rheological and texture of dairy products. These isolated exopolysaccharides can have biotechnological applications. The presence of LAB strains with exopolysaccharide production potential in kradi cheese promotes kradi cheese as functional food with medicinal properties related to exopolysaccharides.

\section{References:}

[1] Deepak V, Ram Kumar Pandian S, Sivasubramaniam S D, Nellaiah H \& Sundar K (2016a). Optimization of anticancer exopolysaccharide production from probioticLactobacillus acidophilus by response surface methodology. Preparative Biochemistry and Biotechnology 46(3) 288-297. 
[2] Deepak V, Ramachandran S, Balahmar R M, Pandian S R K, Sivasubramaniam S D, Nellaiah, H \& Sundar K (2016b). In vitro evaluation of anticancer properties ofexopolysaccharides from Lactobacillus acidophilus in colon cancer cell lines. In VitroCellular \& Developmental Biology - Animal 52(2) 163-173.

[3] Bernal P \& Llamas M A (2012). Promising biotechnological applications of antibiofilm exopolysaccharides. Microbial Biotechnology 5(6) 670-673.

[4] Punoo H A, Patil GR, Singh RRB. (2018a) Textural and microstructural properties of Kradi cheese (an indigenous cheese of Jammu and Kashmir, India). International Journal of Dairy Technology, 71, 2,372-381 .

[5] Punoo HA, Patil GR, Singh RRB (2018b) Physico-chemical and microbiological composition of Kradi cheese. Indian Journal of Dairy Science, 71 (2), 152-155

[6] Ruas-Madiedo P, Hugenholtz J \& Zoon P (2002). An overview of the functionality of exopolysaccharides produced by lactic acid bacteria. International Dairy Journal 12(2-3) $163-171$.

[7] Abedfar A \& Hossininezhad M (2016). Overview of the most important characterization of exopolysaccharides produced by probiotics bacteria and their biologicalfunction. Journal of Environmental Science, Toxicology and Food Technology10 47-55.

[8] Patel S, Majumder A \& Goyal A (2012). Potentials of exopolysaccharides from lactic acid bacteria. Indian Journal of Microbiology 52(1) 3-12.

[9] Ciszek-Lenda M (2011). Biological functions of exopolysaccharides from probiotic bacteria. Central European Journal of Immunology 36 51-55.

[10] Grosu-Tudor S S \& Zamfir M (2013). Functional properties of lactic acid bacteria isolated from Romanian fermented vegetables. Food Biotechnology 27235 - 248.

[11] Van DerMeulen R, Grosu-Tudor SS, Mozzi F, Vaningelgem F, Zamfir M, DeValdez G F \& DeVuys L (2007). Screening of lactic acid bacteria isolates from dairy and cereal products forexopolysaccharide production and genes involved. Int. J. Food Microbiol.118 $250-258$.

[12] Grosu-Tudor S S, Zamfir, Van DerMeulenR \& DeVuysL (2013). Isolation of novel homopolysaccharide producing lactic acid bacteria from Romanian raw milk and fermented dairyproducts. Eur. Food Res. Technol. $237609-615$.

[13] De Man, J.C., Rogosa, M., \& Sharpe, M.E. (2013). A medium for the cultivation of lactobacilli. J. Appl.Bacteriol.23 130 - 135(2013).

[14] DeVusy L, Vanderveken F, Van DerVenS \& Degees B (1998). Production by and isolation ofexopolysaccharides from Streptococcus thermophilus grown in a milk 
medium and evidence for theirgrowth-associated biosynthesis. J. Appl. Microbiol.84 $1059-1068$.

[15] Wall P E (2005). Thin layer chromatography. A modern practical approach.The Royal Society of ChemistryThomas Graham House Cambridge, UK.

[16] Ullrich M (2009). Bacterial polysaccharides. Current innovation and future trends. Jacobs University Bremen,28759 Bremen, Germany. 